OPEN ACCESS

Edited by:

Paola Gauffin-Cano, CONICET Centro de Referencia para Lactobacilos (CERELA), Argentina

Reviewed by: Anandh Babu Pon Velayutham, The University of Utah, United States Sebastian Torres, Instituto de Bioprospección y Fisiología Vegetal (INBIOFIV), Argentina

${ }^{*}$ Correspondence: Zecharia Madar zecharia.madar@mail.huji.ac.il

Specialty section This article was submitted to Nutrition and Metabolism a section of the journal Frontiers in Nutrition

Received: 13 March 2021 Accepted: 22 June 2021 Published: 28 July 2021

Citation:

Zandani G, Anavi-Cohen S, Tsybina-Shimshilashvili N, Sela N, Nyska A and Madar Z (2021) Broccoli

Florets Supplementation Improves

Insulin Sensitivity and Alters Gut Microbiome Population-A Steatosis Mice Model Induced by High-Fat Diet.

Front. Nutr. 8:680241

doi: 10.3389/fnut.2021.680241

\section{Broccoli Florets Supplementation Improves Insulin Sensitivity and Alters Gut Microbiome Population-A Steatosis Mice Model Induced by High-Fat Diet}

\author{
Gil Zandani ${ }^{1}$, Sarit Anavi-Cohen ${ }^{2}$, Nina Tsybina-Shimshilashvili ${ }^{1}$, Noa Sela ${ }^{3}$, \\ Abraham Nyska ${ }^{4}$ and Zecharia Madar ${ }^{1 *}$
}

${ }^{1}$ The Faculty of Agriculture, Food and Environment, The Hebrew University of Jerusalem, Rehovot, Israel, ${ }^{2}$ Peres Academic Center, Rehovot, Israel, ${ }^{3}$ Department of Plant Pathology and Weed Research, Volcani Center, Rishon LeZion, Israel, ${ }^{4}$ Sackler School of Medicine, Tel Aviv University, Tel Aviv, Israel

Nonalcoholic fatty liver disease (NAFLD) is linked to obesity, type 2 diabetes, hyperlipidemia, and gut dysbiosis. Gut microbiota profoundly affects the host energy homeostasis, which, in turn, is affected by a high-fat diet (HFD) through the liver-gut axis, among others. Broccoli contains beneficial bioactive compounds and may protect against several diseases. This study aimed to determine the effects of broccoli supplementation to an HFD on metabolic parameters and gut microbiome in mice. Male (7-8 weeks old) C57BL/J6 mice were divided into four groups: normal diet (ND), high-fat diet (HFD), high-fat diet+10\% broccoli florets (HFD + F), and high-fat diet $+10 \%$ broccoli stalks (HFD + S). Liver histology and serum biochemical factors were evaluated. Alterations in protein and gene expression of the key players in lipid and carbohydrate metabolism as well as in gut microbiota alterations were also investigated. Broccoli florets addition to the HFD significantly reduced serum insulin levels, HOMA-IR index, and upregulated adiponectin receptor expression. Conversely, no significant difference was found in the group supplemented with broccoli stalks. Both broccoli stalks and florets did not affect fat accumulation, carbohydrate, or lipid metabolism-related parameters. Modifications in diversity and in microbial structure of proteobacteria strains, Akermansia muciniphila and Mucispirillum schaedleri were observed in the broccoli-supplemented HFD-fed mice. The present study suggests that dietary broccoli alters parameters related to insulin sensitivity and modulates the intestinal environment. More studies are needed to confirm the results of this study and to investigate the mechanisms underlying these beneficial effects.

Keywords: broccoli, NAFLD, gut microbiome, insulin sensitivity, lipid metabolism, high-fat diet 


\section{INTRODUCTION}

Nonalcoholic fatty liver disease (NAFLD) is one of the major causes of liver disease worldwide (1). The prevalence of NAFLD in the general population is about $25 \%$ and is still increasing (2). NAFLD is a broad term, describing several liver pathologies, ranging from simple hepatic steatosis that is considered benign through steatohepatitis, fibrosis, and, finally, cirrhosis (3). NAFLD is a multisystem disease associated with obesity, insulin resistance, type 2 diabetes mellitus, hyperlipidemia, and metabolic syndrome (2). Microbiota-derived bioactive transition through the gut-liver axis seems to play a pivotal role in the development, progress, and severity of NAFLD (4).

Several factors, inherited as well as acquired, have been implicated in the pathogenesis and pathophysiology of NAFLD, including genetic diversity, epigenomic alterations, sedentary lifestyle, and prolonged positive energy balance (5). However, despite extensive ongoing research, the exact mechanisms are still obscure and most likely involve interactions between multiple organs and tissues (6). Numerous studies highlight the fundamental role of balanced nutrition in NAFLD prevention and treatment $(5,7)$. Despite the complexity and the high variability that exists between patients with NAFLD (8). healthy diets remain the first line of treatment for NAFLD. Recently, the integration of herbal bioactive molecules and medicinal plants has revealed their beneficial role along with lifestyle interventions in NAFLD treatment (9).

Brassica vegetables belong to the Cruciferous family. These include several popular vegetables like kale, cabbage, cauliflower, and broccoli. They contain trace amounts of fat and are rich in vitamins, minerals, and fibers, as well as many phytochemicals (10). Broccoli is known for its beneficial properties (11), which are usually attributed to its high glucosinolates (especially glucoraphanin) and isothiocyanates (mainly sulforaphane) content $(10,12,13)$. Previous data indicated sulforaphane can modulate lipid metabolism and render the antioxidant capacity in vivo and in vitro (14). The metabolic advantages elicit by glucoraphanin, the precursor of sulforaphane, are also supported. Glucoraphanin has been shown to efficiently affect parameters that are related to obesity, insulin resistance, and NAFLD (15). In vivo models, along with human studies, show that glucoraphanin administration improves the lipid profile, fat metabolism, gut microflora composition, and inflammatory factors $(16,17)$. However, one of the drawbacks of interpreting the results of these studies to an everyday diet is the fact that these studies utilized purified or semipurified compounds instead of whole broccoli (12).

The present study aimed to explore the impact/s of whole (as is) dietary broccoli (florets or stalks) consumption on hepatic glucose and fat metabolism and the consequent changes in the bacterial populations in gastrointestinal microbiota.

\section{MATERIALS AND METHODS}

\section{Broccoli Preparation and Analysis}

Frozen broccoli florets and stalks were provided by Sunfrost, Israel. Florets and stalks (10\% by weight) were grounded into homogenic mash before being added to the experimental diets. Broccoli analysis of macronutrients, fiber, and moisture is presented in Supplementary Table 1.

\section{Experimental Animals and Diets}

Male C57BL/6J mice, 7-8 weeks old, were purchased from Harlan Laboratories (Jerusalem, Israel). All animal care and experimental protocols were performed within the guidelines of the Authority for Biological and Biomedical Models, and were approved by the Institutional Animal Care Ethics Committee, both of the Hebrew University of Jerusalem (AG-19-15838-3). Mice were housed under standardized conditions for animal facilities: controlled environment (12-h light/dark cycle, $18-24^{\circ} \mathrm{C}$ room temperature). All mice had free access to food and water. After an adaptation period, 32 mice were randomly divided into four groups $(n=8)$ : (1) the mice fed a normal diet (ND), (2) the mice fed a high-fat (60\%) diet (HFD), (3) the mice fed a highfat diet $+10 \%$ broccoli florets (HFD + F), and (4) the mice fed a high-fat diet $+10 \%$ broccoli stalks (HFD $+S$ ) for 17 weeks. Pelleted form of each of those diets was prepared by mixing water into the powdered diet. The pellets were air-dried and were stored at $-20^{\circ} \mathrm{C}$. Fresh diets were provided weekly. Body weight and food intake were monitored one time a week. Diet compositions are presented in Supplementary Table 2.

\section{Oral Glucose Tolerance Test}

Oral glucose-loading tests were performed at week 15 of the experimental period. Prior to the OGTT, the mice fasted for $12 \mathrm{~h}$, and then were weighed and marked. At time 0 , an initial baseline glucose measurement was taken. The mice were then given D-glucose (3-g/kg body weight) via gavage. Glucose levels in the blood samples were obtained from tail veins and measured at 30,60, and $120 \mathrm{~min}$ after glucose loading with a glucometer (handheld Optimum XceedGlucometer, Abbott Diagnostic Care Ltd.).

\section{Homa-IR}

The insulin resistance index was estimated by the homeostasis model assessment (HOMA) parameter, using the following equation: HOMA $=$ fasting serum insulin $(\mu \mathrm{U} / \mathrm{ml}) \times$ fasting plasma glucose $(\mathrm{mM}) / 22.5$ (18).

\section{Animal Sacrifice and Organ Collection}

At the end of the experiment, the mice fasted overnight, their body weight was recorded, and they were sacrificed in a random order by isoflurane (Minard Inc., USA) anesthesia. Blood was collected from the vena cava, centrifuged at $8,000 \mathrm{rpm}$ at $4^{\circ} \mathrm{C}$ for $10 \mathrm{~min}$, and stored at $-80^{\circ} \mathrm{C}$. Adipose tissue was removed, weighed, placed in liquid nitrogen, and stored at $-80^{\circ} \mathrm{C}$. Liver tissue was collected and weighed. A small sample from the right liver lobe was placed in $4 \%$ formaldehyde, and the remaining liver tissue was minced in liquid nitrogen and stored at $-80^{\circ} \mathrm{C}$. The ceca were separated from the large intestines, and their contents were collected for microbiota analysis.

\section{Biochemical Analysis of Serum Parameters}

Liver enzymes, such as serum alanine aminotransferase (ALT), alkaline phosphatase (ALP), and serum aspartate 
aminotransferase (AST), were measured by an automated clinical chemistry analyzer along with total cholesterol, high density lipoprotein (HDL), and total triglycerides (American Laboratories Ltd., Herzliya, Israel). Concentrations of plasma insulin were determined by a Rat/Mouse Insulin ELISA Kit (Cat \#EZRMI-13K), supplied by Merck.

\section{Liver Histology Examination}

Histological slides were prepared by Patholab (Rehovot, Israel). Livers were macro-dissected, placed in plastic cassettes, and dehydrated. The dehydrated samples were embedded in paraffin blocks by an automatic apparatus. Serial sections 3-5- $\mu$ m thick were cut from each block, placed on glass slides, stained with hematoxylin and eosin ( $\mathrm{H}$ and $\mathrm{E})$, and covered by an automatic apparatus. The histopathological examinations were performed by Dr. Abraham Nyska, DVM, Dipl. ECVP, Fellow IATP, board certified in toxicologic pathology-https:/ebvs.eu/colleges/ ECVP/members/prof-abraham-nyska. Histopathological changes were described and scored by the study pathologist, using semiquantitative grading of five grades (0-4), taking into consideration the severity of the changes. The scoring reflects the predominant degree of the specific lesions seen in the entire field of the histology section. A generic grading criterium was used: (19) zero (0) = no lesion; $1=$ minimal change; $2=$ mild change; $3=$ moderate change; and $4=$ marked change.

\section{Hepatic Lipid Extraction}

Quantification of total lipids in the liver was carried out, using the Folch method (20). Frozen liver tissue (100 mg) was homogenized with $700-\mu \mathrm{L}$ methanol. Then, $1,400 \mu \mathrm{L}$ of chloroform was added $(2: 1 \mathrm{v} / \mathrm{v})$ and lightly shaken overnight to separate the two phases. On the next day, the vials were centrifuged at 3,000 rpm for $10 \mathrm{~min}$ at room temperature. The upper aqueous phase was removed, and the lower organic phase (containing the lipids) was transferred to a clean, previously weighed tube. The samples were evaporated until complete dryness, measured to determine the lipid fraction weight, and normalized to initial tissue sample weight.

\section{Western Blot Analysis}

Liver tissues were lysed with a lysis buffer, containing 20-mM Tris- $\mathrm{HCl}$ (pH 7.4), 145-mM NaCl, 10\% glycerol, 5-mM EDTA, $1 \%$ Triton X-100,.5\% NP-40, 100-mM phenylmethylsulfonyl fluoride (PMSF), 200-mM NaVO4, 5-mM NaF, and 1\% protease inhibitor cocktail. Lysates were centrifuged at 14,000 rpm for $15 \mathrm{~min}$, and the protein concentration was determined by the Bradford method, using bovine serum albumin as a standard. The samples were then separated by SDS-PAGE gel (10\%) and transferred to nitrocellulose membranes. Blots were respectively incubated with dilutions of primary antibodies: (AMPK 1:5,000, \#2532 Cell Signaling Technology; p-AMPK 1:5,000, \#2531 Cell Signaling Technology; ACC 1:1,000, \#3662 Cell Signaling Technology; p-ACC 1:1,000 \#3661 Cell Signaling Technology; AKT 1:5,000 \#9272 Cell Signaling Technology; p-AKT 1:1,000, \#9271 Cell Signaling Technology; $\beta$ actin 1:1,000, \#3700 Cell Signaling Technology; CD36 1:1,000, ab124515 ABCAM) at $4^{\circ}$ overnight. After several washes, the membranes were incubated with a secondary goat antibody (Jackson Immuno-Research Laboratories, West Grove, PA, USA). The immune reaction was detected by enhanced chemiluminescence, with bands being quantified by densitometry and expressed as arbitrary units. $\beta$-actin was used as a control protein.

\section{Quantitative Real-Time PCR}

Total RNA was isolated from liver tissues by using Tri-Reagent (Sigma-Aldrich, Rehovot, Israel), according to the protocol of the manufacturer. Complementary DNA was prepared with the High-Capacity cDNA Reverse Transcription Kit (Quanta BioSciences, Gaithersburg, MD, USA). Real-time polymerase chain reaction (PCR) was performed using the 7300 RealTime PCR System (Applied Biosystems, Foster City, CA, USA), with specific primers as follows: glucose 6-phosphatase (G6pase); phosphoenolpyruvatecarboxykinase (PEPCK); fatty acid synthase (Fasn); peroxisome proliferator-activated receptor alpha (PPAR $\alpha)$; sterol regulatory element-binding protein 1c (SREBP-1c); peroxisome proliferator-activated receptor gamma coactivator 1-alpha (PGC-1 $\alpha$ ); adiponectin receptor 1 (AdipoR1); adiponectin receptor 2 (AdipoR2). Quantitative changes in gene expression were determined by normalizing to 18S. The primer sequences are listed in Supplementary Table 3.

\section{Gut Microbiota Analysis}

The effects of each diet on the bacterial population in the gut microbiome were examined by analyzing the prokaryotic 16S ribosomal RNA gene (16S rRNA), which is approximately 1,500 bp long and contains nine variable regions interspersed among conserved regions. These variable regions were subjected to phylogenetic classification, in diverse microbial populations.

The following protocol describes a two-step PCR-based method for preparing samples for sequencing the variable V3 and V4 regions of the $16 \mathrm{~S}$ rRNA gene. Bacterial DNA was extracted from fecal samples by using the DNeasyPowersoil kit (Qiagen) according to the instructions of the manufacturer. Each sample was then quantified with a Qubit 2.0 Fluorometer (ThermoFisher Scientific, Waltham, MA, USA) and diluted to a final concentration of $5 \mathrm{ng} \mu \mathrm{L}-1$ in $10-\mathrm{mM}$ Tris at $\mathrm{pH}$ 8.5. The $16 \mathrm{~S}$ library preparation was carried out as described in Illumina's 16 S sample preparation guide with minor modifications. PrimeStar HS DNA Polymerase Premix (TakaraClontech, Mountain View, CA, USA) was used instead of the PCR enzyme. Sequences with 97\% similarity were assigned to the same operational taxonomic units (OTU). OTUs of representative sequences at a similarity of $97 \%$ and their relative abundances were used to calculate and analyze rarefaction curves. Bacterial richness and diversity within samples were classified by $\alpha$ diversity (Pielou's index, observed-species indices, and Shannon index).

\section{Statistical Analysis}

Results are presented as mean \pm SEM. Data were analyzed by the JMP 14 Pro software suites (SAS Institute, Cary, NC, USA). Comparisons between groups were made by one-way analysis of variance (ANOVA), followed by a Tukey-Kramer test or by 
unpaired two-tailed Student's T-test. Statistical significance was defined at $p<0.05$.

\section{RESULTS}

\section{Effects of Dietary Broccoli on Body and Tissue Weight and Food Intake}

Consumption of an HFD led to a significant increase in body weight, epididymal fat, and liver weight (Table 1). These parameters were equally elevated in all HFD-fed groups, regardless of whether the diet was supplemented with broccoli (florets or stalks) or not. Consistent with the alterations in body weight, food intake was similar in the HFD-fed groups (Table 1).

\section{Broccoli Enrichment Affects Parameters Related to Glucose Homeostasis}

A glucose tolerance test was performed on the 15th week of the feeding period. Along the entire OGTT, basal blood glucose was markedly elevated in the HFD-fed groups. The ND group exhibited significantly lower glucose levels compared with the other groups, while all HFD-fed mice showed no significant differences at any of the time points (Figure 1A). At the end of the diet regime, fasting blood glucose and serum insulin levels were determined, and the HOMA-IR index was calculated thereafter.

All the HFD-fed groups exhibited increased glucose blood levels in comparison with the ND group. However, blood insulin levels were significantly lower in the group that was supplemented with broccoli florets (Figures 1B,C). This resulted in lower HOMA-IR values in the broccoli florets supplemented group (Figure 1D).

\section{Effects of Broccoli Supplementation on the Serum Lipid Profile, Liver Enzymes, Lipid Content, and Liver Histology}

Table 2 demonstrates the changes in serum lipids levels. Total triglyceride levels of all HFD-fed groups were profoundly lower than in the ND group, whereas a reversed pattern was observed for total blood cholesterol and HDL levels.

Serum ALP levels did not show intergroup differences. Compared with the control, AST and ALT levels were statistically higher only in the broccoli-florets-added group, while their levels did not differ in the other HFD-fed groups.

Liver fat accumulation appeared to increase in all the HFD-fed groups, but only the HFD $+\mathrm{S}$ reached significance (Figure 2A). The results were further substantiated by liver histology $\mathrm{H}$ and $\mathrm{E}$ staining results that were approximately similar to those obtained by the Folch method, although, in this analysis, only the HFD group significantly differed from the control (Figures 2B,C).

\section{Effect of Diets on Markers Involved in Carbohydrate and Fat Metabolism in the Liver}

Further analyses were conducted to evaluate the effect of broccoli addition to HFD on key metabolic regulators. No changes were found in AKT and AMPK activation, assessed by the ratio between phosphorylated to total protein (Figures 3A,B). Conversely, the expression of both adiponectin receptors, AdipoR1, and AdipoR2 was upregulated in the HFD $+F$ group (Figures 3C,D). To further elucidate the metabolic impact of broccoli addition to an HFD, the expression and protein levels of enzymes and factors that participate in hepatic glucose and fat metabolism were examined. p-ACC (ser 79) to the ACC ratio is a surrogate measure for ACC inhibition. Although a tendency toward diminished ACC inhibition was noticed in all HFD-fed groups, this reduction was significantly only in the HFD+F group compared with ND (Figure 4A). Broccoli supplementation (florets or stalks) to HFD negatively affected the expression of FAS (Figure 4B). Consistent with the latter result, lower de novo lipogenesis capacity in the HFD $+\mathrm{S}$ group was also supported by a decrease in SREBP1-c expression (Figure 4C). PGC-1 $\alpha$ expression and CD36 protein levels were unaffected by diet composition (Figures 4D,E). Expression of the key gluconeogenicenzymes, G6pase, and PEPCK was substantially reduced in the two groups that were supplemented with broccoli, compared with the ND group (Figures 4F,G).

\section{Effect of Dietary Broccoli on Microbiota Richness and Diversity, and Mice Gut Bacterial Community}

The interconnection between diet and microbiota composition was assessed at different levels. To evaluate the differences within the samples, the alpha diversity was calculated. The Shannon index, which represents the community diversity and richness, was inferior in the HFD and HFD $+S$ groups compared with that of the control (Table 3). The observed OTU's, which represent the rare species in each group, were found to differ between the HFD + F and the HFD group, with higher levels registered in the former (Table 3). Pielou's index, which indicates species evenness, decreased in the HFD $+S$ group compared with the ND group (Table 3).

Microbiota composition, following the treatments, was evaluated at all taxonomic levels. At the phylum level, Actinobacteria abundance was lower in all HFD groups, while Deferribacteres and Firmicutes abundance decreased only in the HFD $+S$ group and that of the Tenericutes in both broccoli-added groups, compared with the ND group (Figure 5A). Conversely, Verrucomicrobia abundance was markedly increased in the HFD $+\mathrm{S}$ group compared with the ND group (Figure 5A). The Bacteroidetes/Firmicutes ratio was elevated in the HFD $+S$ group compared with the other groups (Figure 5B). At the class level, Clostridia abundance was significantly lower in the stalks group (Figure $5 \mathrm{C}$ ), whereas Betaproteobacteria abundance was significantly elevated in mice fed with broccoli florets compared with the ND group (Figure 5D). Bburkholederiales and Sutterella abundances were increased at the order and genus levels, respectively, in the HFD + F group (Figures 5E,H). At the family level, Alcaligenaceae abundance was statistically higher in the HFD $+\mathrm{F}$ group compared with the other groups (Figure $5 \mathrm{~F}$ ), while mice that were fed with HFD + broccoli stalks showed a reduction in Rikenellaceae abundance compared with the HFD group 
TABLE 1 | Effects of dietary broccoli on body weight, food intake, and tissues weight.

\begin{tabular}{lcccc}
\hline & \multicolumn{3}{c}{ Group } \\
\cline { 2 - 5 } & ND & HFD & HFD + F \\
\hline Initial body weight (g) & $19.79 \pm 0.60^{\mathrm{a}}$ & $19.60 \pm 0.34^{\mathrm{a}}$ & $19.72 \pm 0.42^{\mathrm{a}}$ & $20.39 \pm 0.29^{\mathrm{a}}$ \\
Final body weight (g) & $32.12 \pm 1.64^{\mathrm{b}}$ & $42.19 \pm 1.33^{\mathrm{a}}$ & $43.34 \pm 1.56^{\mathrm{a}}$ & $43.95 \pm 1.67^{\mathrm{a}}$ \\
Food intake (g/day) & $3.44 \pm 0.23^{\mathrm{a}}$ & $2.71 \pm 0.14^{\mathrm{b}}$ & $2.83 \pm 0.16^{\mathrm{b}}$ & $2.75 \pm 0.21^{\mathrm{b}}$ \\
Liver tissue weight (g) & $1.09 \pm 0.08^{\mathrm{b}}$ & $1.76 \pm 0.03^{\mathrm{a}}$ & $1.77 \pm 0.19^{\mathrm{a}}$ & $1.78 \pm 0.19^{\mathrm{a}}$ \\
Adipose tissue weight (g) & $1.16 \pm 0.15^{\mathrm{b}}$ & $1.66 \pm 0.07^{\mathrm{a}}$ & $0.13^{\mathrm{a}}$ & $1.85 \pm 0.06^{\mathrm{a}}$ \\
\hline
\end{tabular}

Male C57BL/6J mice were fed with normal diet (ND), high-fat diet (HFD), HFD + 10\% broccoli florets (HFD + F), HFD + 10\% broccoli stalks (HFD + S) for 17 weeks. Values are expressed as mean \pm SEM $(n=8)$. Means without a common letter are statistically different $(p<0.05)$.

A

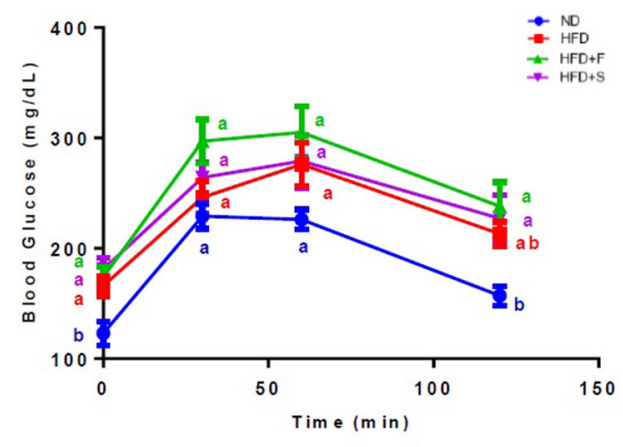

C

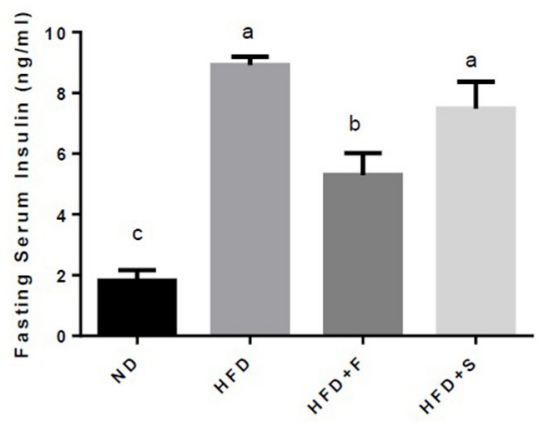

B

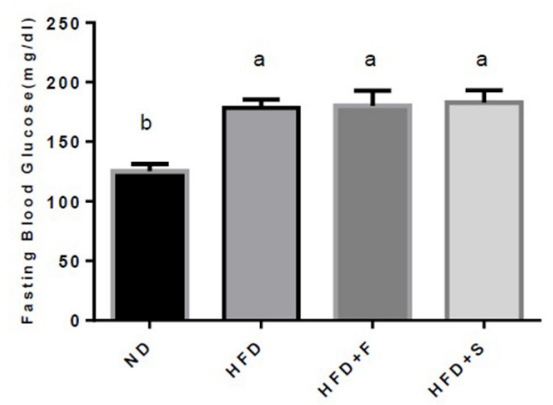

D

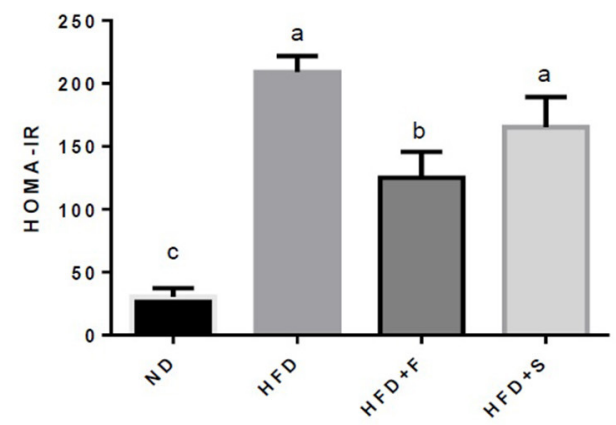

FIGURE 1 | Effects of broccoli enrichment on glucose homeostasis. Male C57BI/6J mice fed a normal diet (NO), high fat diet (HFD), HFD + I0\% broccoli florets (HFO + F), HFD + 10\% broccoli stalks (HFD + S) for 17 weeks. Oral glucose tolerance test (120 min duration) was performed at week 15 (A) Mean fasting blood glucose concentration at sacrifice (B) insulin serum levels at sacrifice (C) and homeostatic model assessment of insulin resistance index (D). Values are expressed as mean \pm SEM $(n=7-8)$. Means without a common letter are statistically different.

(Figure 5G). At the species level, a decrease in the abundance of Mucispirillum schaedleri was observed in the HFD $+\mathrm{F}$ group compared with the HFD $+S$ group (Figure 5I), while the Akkermansia muciniphila community was elevated in the HFD $+S$ group compared with the ND group (Figure 5J).

\section{DISCUSSION}

The present study examined the effects of broccoli supplementation under the conditions of diet-induced liver steatosis. The obtained results demonstrated that, although the addition of broccoli to an HFD did not ameliorate body and tissues weight gain or food intake, it positively improved insulin sensitivity and promoted modifications in gut microbiota composition.

NAFLD is characterized by elevated ALT and AST levels, which reflects nonspecific hepatocellular damage (21). In the present study, serum AST and ALT levels statistically decreased in the stalks-supplemented group compared with the florets group, which exhibited the greatest increase of all the groups. Previous studies showed that broccoli consumption does not 
TABLE 2 | Effects of broccoli supplementation on the serum lipid profile and liver enzymes.

\begin{tabular}{|c|c|c|c|c|}
\hline & \multicolumn{4}{|c|}{ Group } \\
\hline Total triglycerides (mg/dL) & $136.00 \pm 17.48^{\mathrm{a}}$ & $81.87 \pm 5.54^{b}$ & $80.50 \pm 4.15^{\mathrm{b}}$ & $81.00 \pm 3.25^{b}$ \\
\hline Total cholesterol (mg/dL) & $152.60 \pm 15.64^{b}$ & $234 \pm 33.84^{a}$ & $214.25 \pm 13.14^{\mathrm{a}}$ & $220.00 \pm 12.58^{a}$ \\
\hline $\mathrm{HDL}(\mathrm{mg} / \mathrm{dL})$ & $122.10 \pm 10.35^{b}$ & $170.93 \pm 12.83^{a}$ & $165.68 \pm 14.15^{\mathrm{a}}$ & $163.00 \pm 9.57^{a}$ \\
\hline ALP (IU/L) & $76.60 \pm 2.18$ & $68.87 \pm 4.82$ & $69.25 \pm 5.07$ & $68.00 \pm 3.95$ \\
\hline AST/SGOT (IU/L) & $69.25 \pm 7.69^{b}$ & $110.63 \pm 13.86^{\mathrm{ab}}$ & $146.25 \pm 17.04^{\mathrm{a}}$ & $88.00 \pm 11.39^{b}$ \\
\hline ALT/SGPT (IU/L) & $40.00 \pm 8.50^{b}$ & $73.42 \pm 9.95^{b}$ & $131.00 \pm 15.83^{\mathrm{a}}$ & $82.00 \pm 13.08^{b}$ \\
\hline
\end{tabular}

Male C57BL/6J mice were fed with normal diet (ND), high-fat diet (HFD), HFD + 10\% broccoli florets (HFD + F), HFD + 10\% broccoli stalks (HFD + S) for 17 weeks. Values are expressed as mean \pm SEM $(n=8)$. Means without a common letter are statistically different $(p<0.05)$.

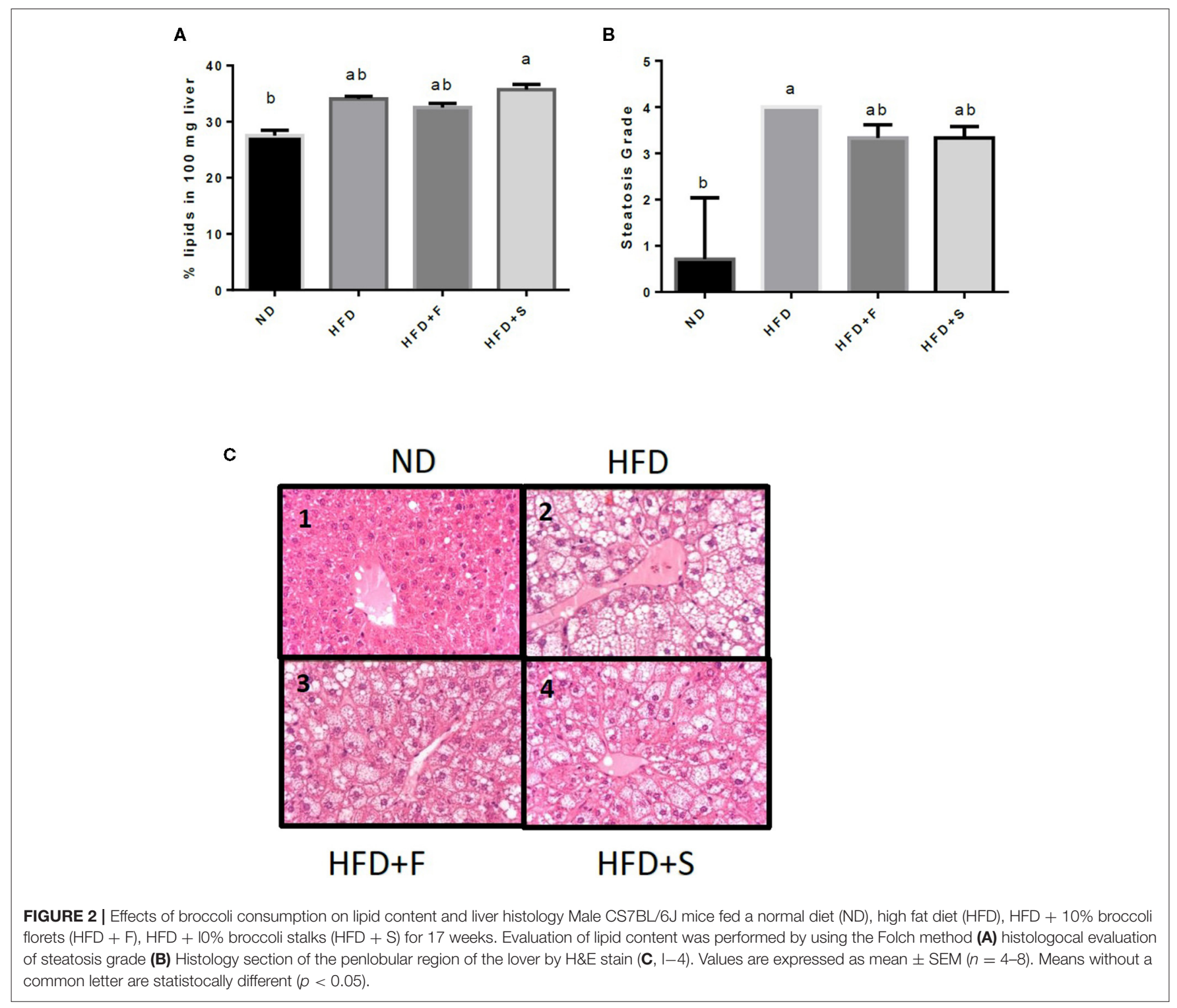




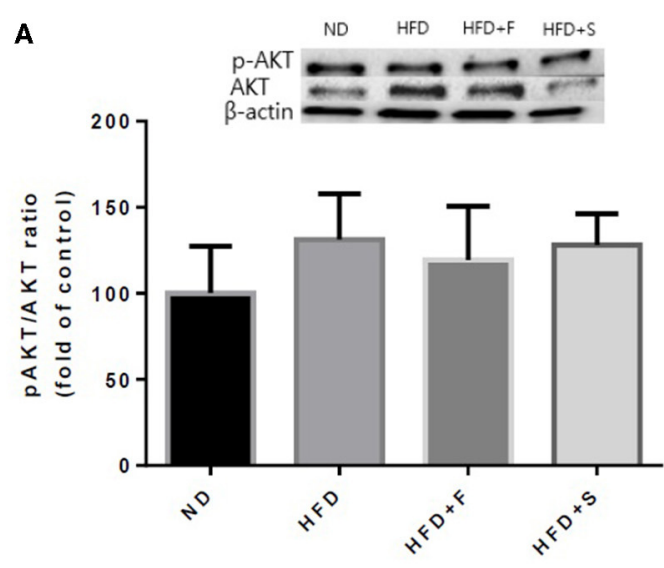

c

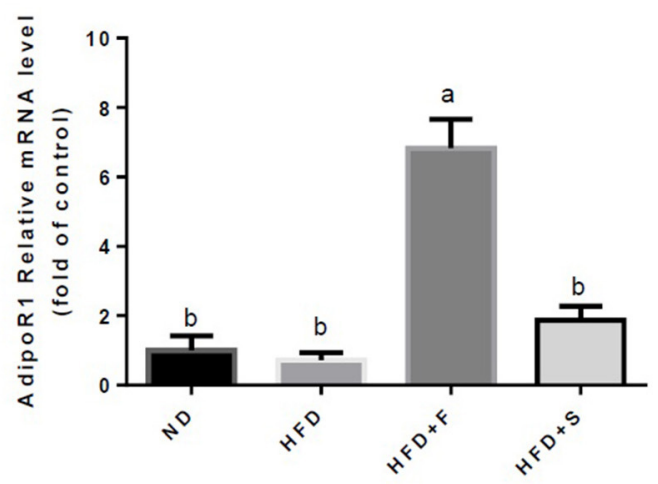

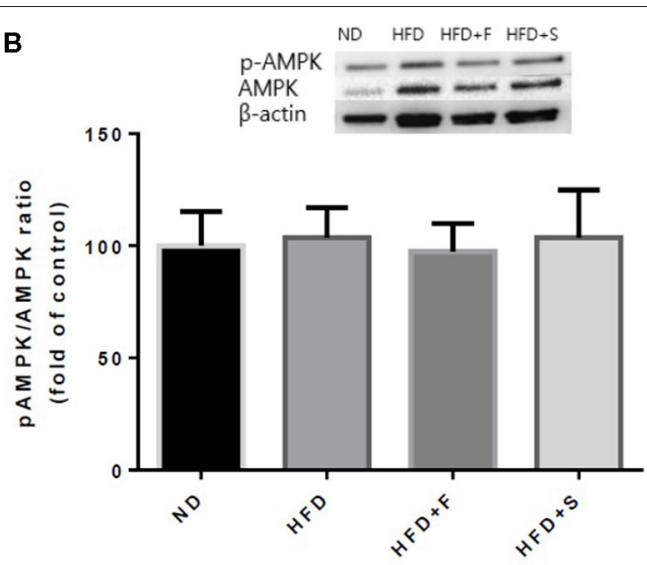

D

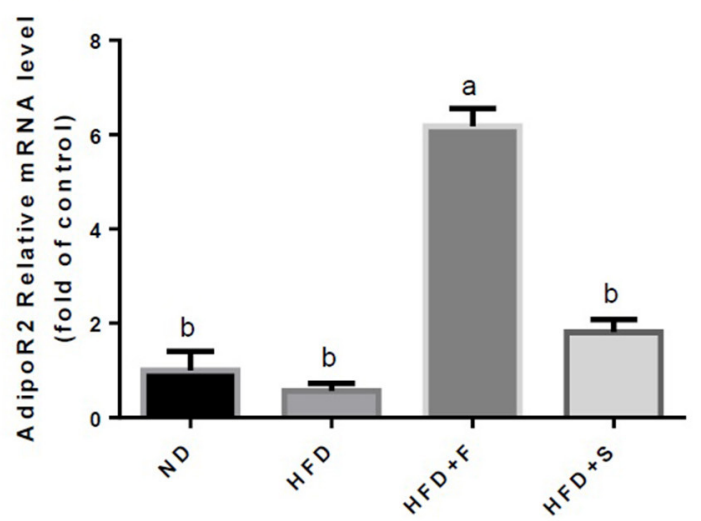

FIGURE 3 | Effect of broccoli supplementation on markers involved in carbohydrates and fat metabolism in the liver. Male C57BI/6J mice fed a normal diet (ND), high fat diet (HFD), HFD + 10\% broccoli florets (HFD + F), HFD + 10\% broccoli stalks (HFD + S) for 17 weeks. Protein levels and gene expression of p-AKT/AKT (A) p-AMPK/AMPK (B) AdipoRI (C) and AdipoR2 (D) were measured. Values are expressed as mean \pm SEM. Means without a common letter are statistically different $(p$ $<0.05)$

affect ALT and AST levels (22, 23). Contreras-Zentella et al. reported that a drastic increase of liver transaminase activities in the serum, which was suggested to be considered as an index marker of hepatotoxicity, does not necessarily reflect liver cell death (24). Vegetables with high concentrations of glucosinolates, such as broccoli, naturally contain goiterogens, which were found to lower thyroid hormones levels (25). A recent study has found a relationship between lower thyroid gland functionality and the severity of liver damage (26). This, possibly, can explain why mice supplemented with broccoli demonstrated higher exacerbation in liver tissue. This might also explain the enigmatic increase in liver enzymes in mice supplemented with broccoli florets.

Elevated liver enzymes in the $\mathrm{HFD}+\mathrm{F}$ group appear to be independent of liver fat accumulation or the degree of steatosis. Indeed, all the HFD-fed groups demonstrated comparable fat accumulation with no marked effect for broccoli supplementation. Moreover, in the current study, blood TG levels were significantly lower in all the HFD-fed mice, compared with the control. Previous studies conducted in mice with the same or closely related genetic background as this study (B6J and B6N) also reported decreased TG levels, following the consumption of an $\operatorname{HFD}(27,28)$. Although not tested, several explanations may account for this phenomenon, including that HFD consumption induced increased hepatic TG clearance and/or decreased hepatic TG export. Similarly, increased HDL blood levels, following the consumption of an HFD, was also previously observed (29, 30). Nevertheless, HDL levels are not indicators reliable for functionality of this lipoprotein nor the individual atherogenic risk (31).

Liver fat metabolism was not significantly affected by the broccoli addition to the HFD as all the HFD-fed groups did not differ from one another. However, FAS expression tended to decrease, to a greater extent, in both broccoli-supplemented groups and, in contrast to the HFD group, reached significance compared with the control, ND group. A similar pattern was observed in ACC activation and SREBP-1c expression in the $\mathrm{HFD}+\mathrm{F}$ and $\mathrm{HFD}+\mathrm{S}$ groups, respectively. It can be speculated that a longer time period would have intensified the outcome of the observed differences in lipogenesis between the groups. 
A

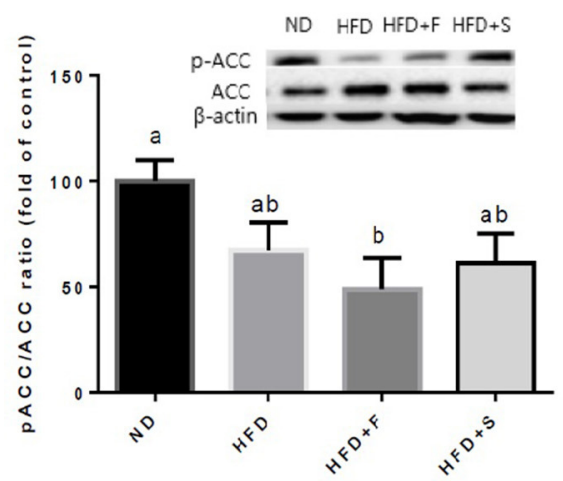

C

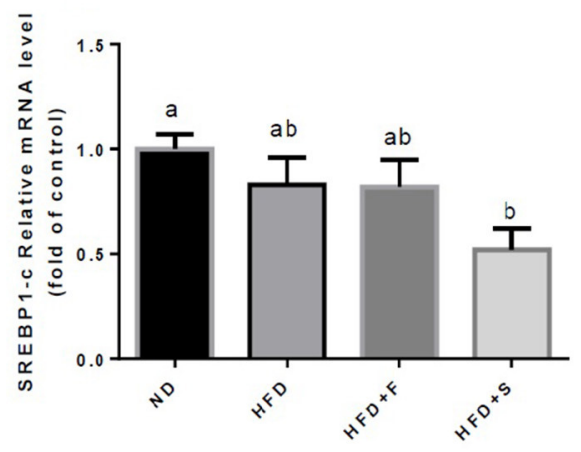

E

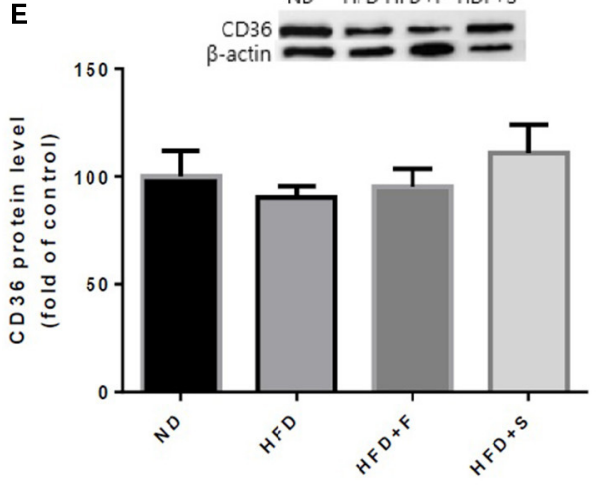

B

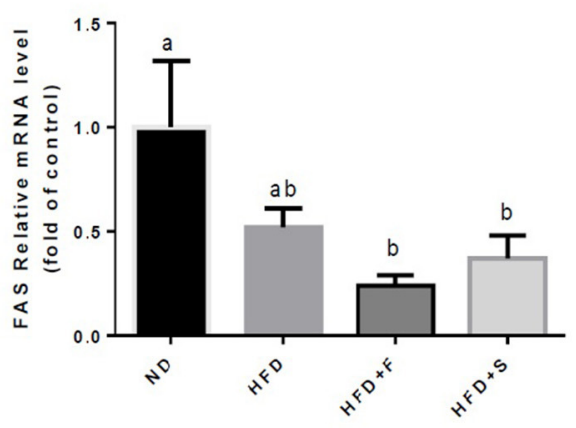

D

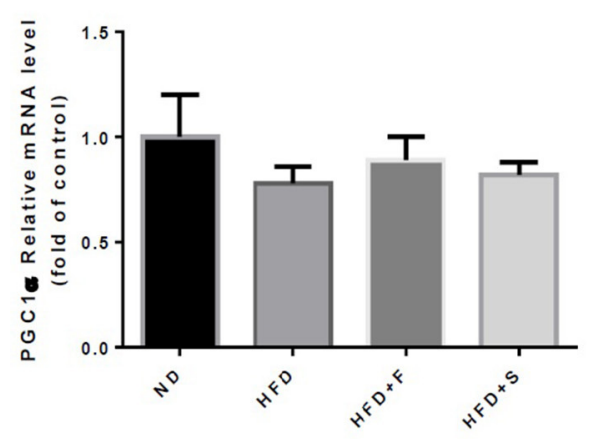

F

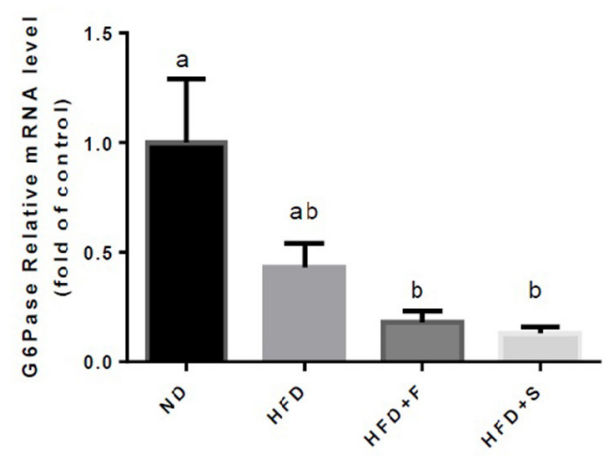

G

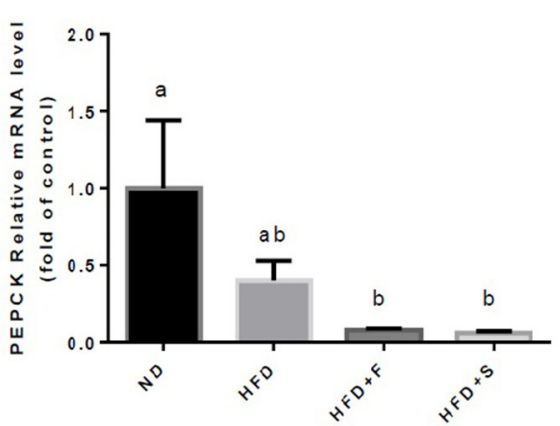

FIGURE 4 | Effect of broccoli supplementation on markers involved in liver fat metabolism. Male C57BL/6J mice fed a normal diet (ND), high fat diet (HFD), HFD + $10 \%$ broccoli florets (HFD + F), HFD + 10\% broccoli stalks (HFD + S) for 17 weeks. Protein levels and genes expression of p-ACC/ACC (A) FAS (B) SREBPI-c (C) PGC-Ia (D) CD36 (E) G6pase (F) and PEPCK (G) were measured. Values are expressed as mean \pm SEM. Means without a common letter are statistically different $(p$ $<0.05)$. 
TABLE 3 | Dietary broccoli impact on microbiota richness and diversity.

\begin{tabular}{lrrrr}
\hline & ND & HFD & HFD + F & HFD + S \\
\hline Shannon index & $5.98 \pm 0.03^{\mathrm{a}}$ & $5.61 \pm 0.05^{\mathrm{b}}$ & $5.82 \pm 0.06^{\mathrm{ab}}$ & $5.62 \pm 0.06^{\mathrm{b}}$ \\
Observed OUTs & $124.60 \pm 2.29^{\mathrm{ab}}$ & $112.00 \pm 2.65^{\mathrm{b}}$ & $128.00 \pm 3.67^{\mathrm{a}}$ & $123.00 \pm 3.35^{\mathrm{ab}}$ \\
Pielou's index & $0.86 \pm 0.01^{\mathrm{a}}$ & $0.82 \pm 0.01^{\mathrm{ab}}$ & $0.83 \pm 0.01^{\mathrm{ab}}$ & $0.81 \pm 0.01^{\mathrm{b}}$ \\
\hline
\end{tabular}

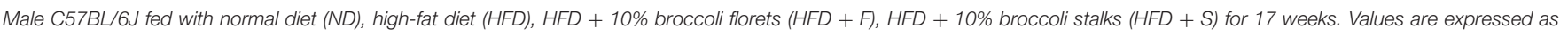
mean $\pm \operatorname{SEM}(n=5)$. Means without a common letter are statistically different $(p<0.05)$.

Although additional extended work is required, this inference is substantiated by the results of Chen et al., in which broccoli intervention through diet did lead to a reduction in liver weight but, similar to our study, did not reduce final body weight, food intake, or fat mass (23).

Insulin sensitivity is metabolically altered by HFD. Here, HFD consumption triggered an increase in serum insulin concentration and HOMA-IR. However, the addition of broccoli florets profoundly ameliorated HFD-induced insulin resistance (32). The positive effects observed due to broccoli florets addition to the HFD might be related to glucosinolates found in broccoli. Previous studies, which administered isolated bioactive compounds from broccoli, sulphoraphane, or glucoraphanin, demonstrated improvements in insulin resistance and glucose tolerance $(16,33)$. It is known that glucosinolate content is lower in stems and roots (34). Therefore, reduced concentrations of these secondary metabolites may account for the lack of effect of the stalks supplementation on insulin and glucose metabolism.

Disruptions in insulin signaling are tightly associated with NAFLD (35). Akt is an obligate intermediate for proper insulin signaling and plays a central role in the metabolic axis activated by insulin (36). Basal AKT activation, as determined by its phosphorylation at Ser473, remained unchanged in all groups. Yet, as mentioned above, differences in serum insulin concentration and HOMA-IR were observed with $\mathrm{HDF}+\mathrm{F}$. Therefore, it can be argued that higher insulin concentrations were needed in the HFD and HFD $+\mathrm{S}$ groups to lead to the same AKT basal phosphorylation as the group that was supplemented with broccoli florets. However, it must be emphasized that, although AKT is a central player in the insulin pathway, insulin signaling does not solely rely on AKT activation, and several other PI3K-dependent and independent nodes participate to create full effect of insulin (37). Thus, other insulin-dependent pathways could have been differently affected by the broccoli addition.

Indeed, inconsistency exists regarding the influence of HFD on gluconeogenic enzymes expression/activity. Whereas shortterm chronic exposure to an HFD leads to an increase in gluconeogenesis; $(38,39)$ others found no such effect $(40)$. In the current work, G6pase and PEPCK, key enzymes involved in gluconeogenesis, exhibited nonsignificant differences between all HFD groups, although a tendency toward lower expression levels in the broccoli supplemented groups was observed. Thus, longer feeding duration and/or higher broccoli content are needed to reach significance. Given that insulin sensitivity was reduced by
HFD, decreased PEPCK and G6Pase expression appears to occur independently of insulin.

Another dominant player that can profoundly affect lipid and carbohydrate metabolism, including gluconeogenesis inhibition, and is known to augment insulin sensitivity is AMPK. Following its activation, AMPK promotes energyproducing pathways while it "shuts down" energy-consuming pathways (41). This kinase activation is mediated through several factors, including adiponectin. Although not tested directly in the present study, the ability of broccoli-contained component/s to increase adiponectin levels is in agreement with a previous study conducted in HFD-fed rats, which were supplemented with two different doses of broccoli extract (200 or $400 \mathrm{mg} / \mathrm{kg}$ ). There, broccoli extract-treated rats presented higher concentrations of serum adiponectin (32).

Adiponectin exerts its effects through binding and activation of its receptors, adipoR1 and adipoR2 (42). Adiponectin downstream effectors in the liver appear to have been induced in the HFD + F group, at least to some extent, as these hormone receptors were upregulated in this group. However, in contrast to the induction of adiponectin receptors by broccoli florets, AMPK activation remained unaffected by the diet consumed, suggesting this kinase is not the link to the metabolic changes observed. Nevertheless, the expression pattern of these receptors was somewhat correlated with insulin sensitivity in the HFD-fed groups. Indeed, AdipoR1 and AdipoR2 were found to regulate insulin sensitivity in insulin target tissues, and are important in the pathophysiology of insulin resistance (43). The role of adiponectin in the observed increase in insulin sensitivity in the $\mathrm{HFD}+\mathrm{F}$ group remained to be defined.

Emerging evidence provides an argument about the importance of the gut microbiome in influencing host homeostasis. There is a close association between gut microbiota dysbiosis and intestinal disorders. In fact, dysbiosis can be considered as a biomarker of such disorders (44). Recently, dysbiosis has been suggested to play a critical role in promoting metabolic diseases, (45) such as NAFLD and NASH, among others (46).

Consumption of brassica vegetables was linked to alterations in the gut bacterial community $(47,48)$. This is in accord with the role that is ascribed to diet and different environmental factors in maintaining gastrointestinal health (46) and further emphasizes the specific influence of broccoli. 


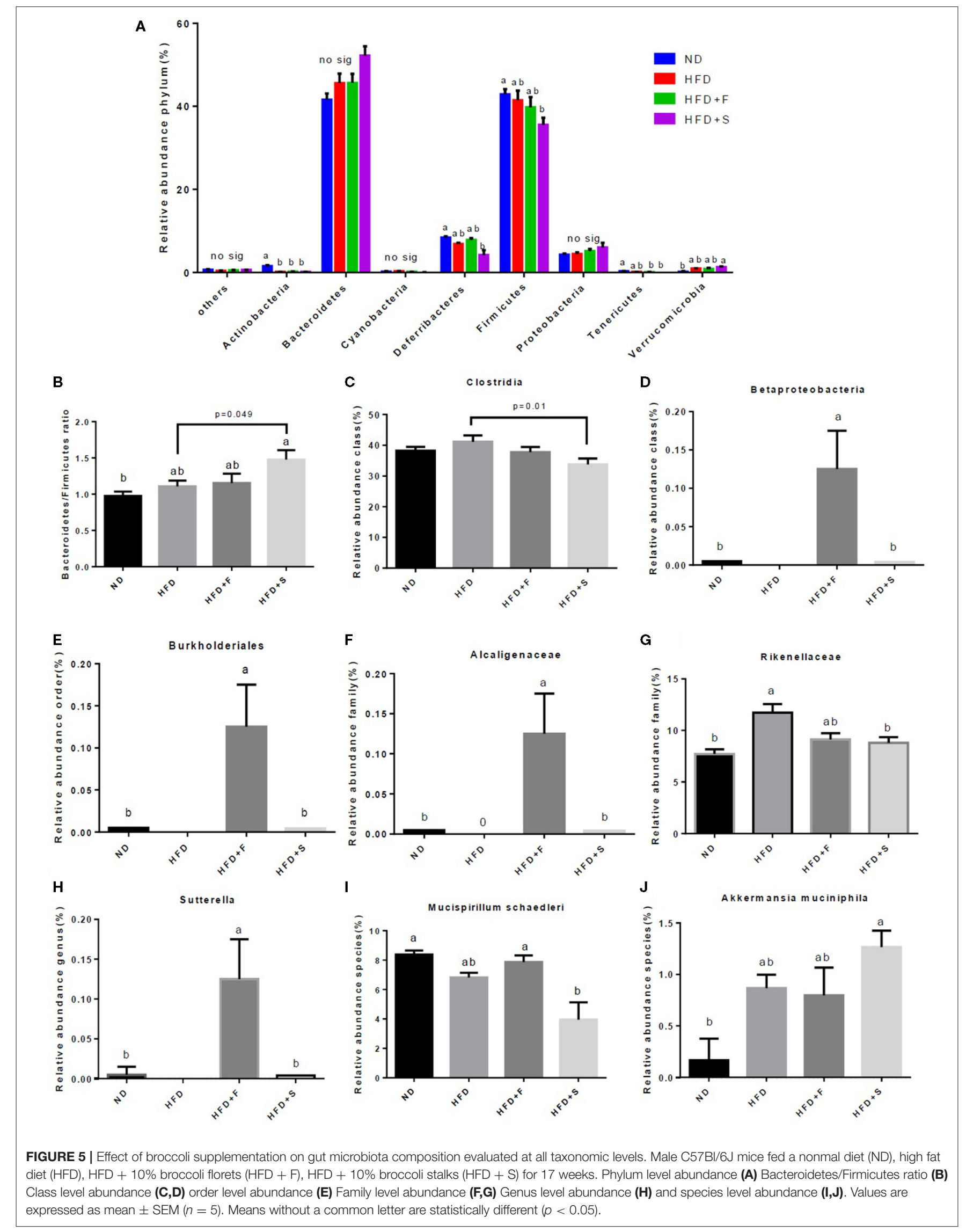


In the present work, several alpha diversity indexes were evaluated. The Shannon index represents the community diversity and richness, which are related to the ability to withstand external threats (44). Although this index was not affected by broccoli consumption, it was significantly lower in all the HFD-fed groups, suggesting reduced diversity compared with the ND group. HFD feeding has been associated with modifications in the gut microbial profile as well as decreased diversity (49), with most studies demonstrating diminished microbiota diversity, independent of the fat percentage in the diet (\% calories) (46). Conversely, in the broccoli floretsupplemented group, we detected an increase in observed OTUs, which represent the rare species in each group. This finding is consistent with previous animal studies, showing that 4 days of broccoli consumption increased the number of OTUs in rats $(50,51)$, although broccoli supplementation in humans did not affect the alpha diversity indexes (52).

Dietary broccoli induced further alterations in the gut bacterial composition. The diversity of dominant gut bacteria, Firmicutes, and Bacteroidetes was shifted toward a higher Bacteroidetes/Firmicutes ratio in the broccoli stalks group. Previous studies performed on the HFD models reported reduced Bacteroidetes/Firmicutes ratios with an increase in this ratio, indicating antiobesity effects $(53,54)$. However, not all works appear to support this trend (55), and, thus, consensus has not been reached.

Other taxonomical levels have also been modified by broccoli consumption. A dramatic increase in Proteobacteria strains (Betaproteobacteria, Burkholederiales, Alcaligenaceae, and Sutterella) was noted, although no significant difference was observed in Proteobacteria phylum abundance. Significant abundance of Betaproteobacteria, Burkholederiales, Alcaligenaceae, and Sutterella was found in a mouse-induced obesity model in comparison with mice supplemented with prebiotics (56). Hiippala et al. (57) showed that the Sutterella genus, which has been suggested to have an immunomodulatory role due to the ability to adhere to intestinal epithelial cells, do not contribute significantly to microbiota dysbiosis.

HFD consumption augmented Clostridia and Rikenellaceae abundance, and a reduction in the broccoli stalks group was observed. As previously described, an elevated Rikenellaceae abundance was found in HFD-fed mice (58-60), along with higher levels of the Clostridia class $(61,62)$. Several works have suggested that elevated Clostridia species may represent a protective factor against allergens, and this elevation also increases IL-22, which improves intestinal permeability $(63,64)$.

Dietary broccoli also affected bacteria that are related to the intestinal mucus layer. A significant reduction was noticed in Mucispirillum schaedleri (Deferribacteres phylum) abundance in the stalks group compared with the florets group. Mucispirillum schaedleri is found in low levels in mammalian intestinal microbiota (65). Microbial dominance of Mucispirillum was associated with proinflammatory responses in the gut microbiota mucosa (66). However, the genetic and physiological features of this species during inflammation and diseases are still not fully understood (67). Akkermansia muciniphila (Verrucomicrobia phylum), which is a mucindegrading community, was elevated in the group that was supplemented with the broccoli stalks. This bacterium resides in the mucus layer and was reported to ameliorate the host metabolic functions and intestinal immunity $(68,69)$. An increase in the Akkermansia species population was found to reduce low-grade inflammation by suppressing the expression of pro-inflammatory cytokins (70) and by preserving gut integrity (71). Furthermore, higher abundance of Akkermansia muciniphila was previously found to be associated with improved glucose metabolism, leading to reduced fasting blood glucose levels $(72,73)$. However, in the present study, insulin and glucose levels remained unchanged, following the consumption of broccoli stalks.

It is important to emphasize that broccoli is a single vegetable and, generally, not eaten alone. Thus the combination with other ingredients in the diet might substantially affect the outcome (11).

\section{CONCLUSIONS}

In summary, addition of broccoli florets to an HFD ameliorated insulin sensitivity manifested by reduced serum insulin and HOMA-IR index. Broccoli florets further promoted gut microbiota diversity and low-grade inflammatory-associated strains. Stalk supplementation also altered gut microbiota, leading to the increased Bacteroidetes/Firmicutes ratio and levels of communities that preserve the mucus layer and gut integrity while simultaneously decreasing the levels of potentially harmful species. Future research is needed to elucidate the roles of dietary broccoli addition in metabolic parameters and to comprehensively define the changes in the gut microbiota and their subsequent outcomes. Also, the bioactive compounds, which may contribute to the described results, required further elucidation.

\section{DATA AVAILABILITY STATEMENT}

Datasets presented in this study can be found in NCBI short reads archive under BioProject accession PRJNA728821.

\section{ETHICS STATEMENT}

The animal study was reviewed and approved by the Hebrew University of Jerusalem's guidelines of the Authority for Biological and Biomedical Models, and was approved by its Institutional Animal Care Ethics Committee (AG-19-15838-3).

\section{AUTHOR CONTRIBUTIONS}

$\mathrm{ZM}$ and GZ conceived the study and drafted the manuscript. SA-C, NT-S, NS, and AN contributed to the methodology 
and data processing. All the authors critically revised the manuscript for intellectual content, approved the final version, and agreed to be accountable for all the aspects of the work.

\section{FUNDING}

This research was partly supported by the Israeli Plants Production and Marketing Board.

\section{REFERENCES}

1. Cotter TG, Rinella M. NAFLD 2020: the state of the disease. Gastroenterology. (2020) 158:1851-64. doi: 10.1053/j.gastro.2020.01.052

2. Younossi ZM. Non-alcoholic fatty liver disease - a global public health perspective. J Hepatol. (2019) 70:531-44. doi: 10.1016/j.jhep.2018.10.033

3. Friedman SL, Neuschwander-Tetri BA, Rinella M, Sanyal AJ. Mechanisms of NAFLD development and therapeutic strategies. Nat Med. (2018) 24:908-22. doi: 10.1038/s41591-018-0104-9

4. Ding Y, Yanagi K, Cheng C, Alaniz RC, Lee K, Jayaraman A. Interactions between gut microbiota and non-alcoholic liver disease: the role of microbiota-derived metabolites. Pharmacol Res. (2019) 141:521-9. doi: 10.1016/j.phrs.2019.01.029

5. Ullah R, Rauf N, Nabi G, UlIah H, Shen Y, Zhou YD, et al. Role of nutrition in the pathogenesis and prevention of non-alcoholic fatty liver disease : recent updates. Int J Biol Sci. (2019) 15:265-76. doi: 10.7150/ijbs.30121

6. Bunney PE, Zink AN, Holm AA, Billington CJ, Kotz CM. Orexin activation counteracts decreases in nonexercise activity thermogenesis (NEAT) caused by high-fat diet. Physiol Behav. (2017) 176:139-48. doi: 10.1016/j.physbeh.2017.03.040

7. Wong VWS. Current prevention and treatment options for NAFLD. Adv Exp Med Biol. (2018) 1061:149-57. doi: 10.1007/978-981-10-8684-7_12

8. Araújo AR, Rosso N, Bedogni G, Tiribelli C, Bellentani S. Global epidemiology of non-alcoholic fatty liver disease/non-alcoholic steatohepatitis: what we need in the future. Liver Int. (2018) 38:47-51. doi: 10.1111/liv.13643

9. Bagherniya M, Nobili V, Blesso CN, Sahebkar A. Medicinal plants and bioactive natural compounds in the treatment of non-alcoholic fatty liver disease : a clinical review. Pharmacol Res. (2018) 130:213-40. doi: 10.1016/j.phrs.2017.12.020

10. Sanlier N Saban GM. The benefits of brassica vegetables on human health. $J$ Hum Heal Res. (2018) 1:104.

11. Latté KP, Appel KE, Lampen A. Health benefits and possible risks of broccoli - an overview. Food Chem Toxicol. (2011) 49:3287-309. doi: 10.1016/j.fct.2011.08.019

12. Jeffery EH, Araya M. Physiological effects of broccoli consumption. Phytochem Rev. (2009) 8:283-98. doi: 10.1007/s11101-008-9106-4

13. Vanduchova A, Anzenbacher P, Anzenbacherova E. Isothiocyanate from broccoli, sulforaphane, and its properties. J Med Food. (2019) 22:121-6. doi: 10.1089/jmf.2018.0024

14. Lei P, Tian S, Teng C, Huang L, Liu X, Wang J, et al. Sulforaphane improves lipid metabolism by enhancing mitochondrial function and biogenesis in vivo and in vitro. Mol Nutr Food Res. (2019) 63:1-13. doi: 10.1002/mnfr.201800795

15. $\mathrm{Xu} \mathrm{L}$, Nagata $\mathrm{N}$, Ota $\mathrm{T}$. Glucoraphanin: a broccoli sprout extract that ameliorates obesity-induced inflammation and insulin resistance. Adipocyte. (2018) 7:218-25. doi: 10.1080/21623945.2018.1474669

16. Xu X, Dai M, Lao F, Chen F, Hu X, Liu Y et al. Effect of glucoraphanin from broccoli seeds on lipid levels and gut microbiota in high-fat diet-fed mice. J Funct Foods. (2020) 68:103858. doi: 10.1016/j.jff.2020.1 03858

17. Armah CN, Derdemezis C, Traka MH, Dainty JR, Doleman JF, Saha S, et al. Diet rich in high glucoraphanin broccoli reduces plasma LDL cholesterol: evidence from randomised controlled trials. Mol Nutr Food Res. (2015) 59:918-26. doi: 10.1002/mnfr.201400863

\section{ACKNOWLEDGMENTS}

The authors thank Sunfrost Israel for supplying the broccoli.

\section{SUPPLEMENTARY MATERIAL}

The Supplementary Material for this article can be found online at: https://www.frontiersin.org/articles/10.3389/fnut.2021. 680241/full\#supplementary-material

18. Heikkinen S, Argmann CA, Champy MF, Auwerx J. Evaluation of glucose homeostasis. Curr Protoc Mol Biol. (2007) Chapter 29:Unit 29B.3. doi: 10.1002/0471142727.mb29b03s77

19. Schafer KA, Eighmy J, Fikes JD, Halpern WG, Hukkanen RR, Long GG, et al. Use of severity grades to characterize histopathologic changes. Toxicol Pathol. (2018) 46:256-65. doi: 10.1177/0192623318761348

20. Folch J, Lees M, Sloane-Stanley GH. A simple method for the isolation and purification of total lipids from animal tissues. J Biol Chem. (1957) 226:497-509. doi: 10.1016/S0021-9258(18)64849-5

21. Neuman MG, Cohen LB, Nanau RM. Biomarkers in nonalcoholic fatty liver disease. Can J Gastroenterol Hepatol. (2014) 28:607-18. doi: $10.1155 / 2014 / 757929$

22. Aranaz P, Navarro-Herrera D, Romo-Hualde A, Zabala M, Lopez-Yoldi M, Gonzalez-Ferrero C, et al. Broccoli extract improves high fat diet-induced obesity, hepatic steatosis and glucose intolerance in Wistar rats. J Funct Foods. (2019) 59:319-28. doi: 10.1016/j.jff.2019.05.054

23. Chen Y, Wallig MA, Jeffery EH. Dietary broccoli lessens development of fatty liver and liver cancer in mice given diethylnitrosamine and fed a western or control diet 1 - 3. J Nutr. (2016) 146:542-50. doi: 10.3945/jn.115.228148

24. Contreras-Zentella ML, Hernández-Muñoz R. Is liver enzyme release really associated with cell necrosis induced by oxidant stress? Oxid Med Cell Longev. (2016) 2016:12. doi: 10.1155/2016/3529149

25. Bajaj JK, Salwan P, Salwan S. Various possible toxicants involved in thyroid dysfunction: A review. J Clin Diagnostic Res. (2016) 10:FE01-3. doi: 10.7860/JCDR/2016/15195.7092

26. Ritter MJ, Amano I, Hollenberg AN. Thyroid hormone signaling and the liver. Hepatology. (2020) 72:742-52. doi: 10.1002/hep.31296

27. Podrini C, Cambridge EL, Lelliott CJ, Carragher DM, Estabel J, Gerdin $\mathrm{AK}$, et al. High-fat feeding rapidly induces obesity and lipid derangements in C57BL/6N mice. Mamm Genome. (2013) 24:240-51. doi: 10.1007/s00335-013-9456-0

28. Biddinger SB, Almind K, Miyazaki M, Kokkotou E, Ntambi JM, Khan CR. Effects of diet and genetic background on sterol rgulatory element-binding protein-1c, stearoyl-CoA desaturase 1, and the development of the metabolic syndrome. Diabetes. (2005) 54:1314-23. doi: 10.2337/diabetes.54.5.1314

29. Sun D, Zhang L, Chen H, Feng R, Cao P, Liu Y. Effects of Antarctic krill oil on lipid and glucose metabolism in C57BL/6J mice fed with high fat diet. Lipids Health Dis. (2017) 16:2-9. doi: 10.1186/s12944-017-0601-8

30. Thompson KJ, Swan RZ, Iannitti DA, McKillop IH, Sindram D. Diet-induced obesity and ethanol impair progression of hepatocellular carcinoma in a mouse mesenteric vein injection model. Surg Endosc. (2013) 27:246-55. doi: 10.1007/s00464-012-2429-7

31. März W, Kleber ME, Scharnagl H, Speer T, Zewinger S, Ritsch A, et al. HDL cholesterol: reappraisal of its clinical relevance. Clin Res Cardiol. (2017) 106:663-75. doi: 10.1007/s00392-017-1106-1

32. Aborehab NM, El Bishbishy MH, Waly NE. Resistin mediates tomato and broccoli extract effects on glucose homeostasis in high fat dietinduced obesity in rats. BMC Complement Altern Med. (2016) 16:1-10. doi: 10.1186/s12906-016-1203-0

33. Bahadoran Z, Tohidi M, Nazeri P, Mehran M, Azizi F, Mirmiran P. Effect of broccoli sprouts on insulin resistance in type 2 diabetic patients: a randomized double-blind clinical trial. Int J Food Sci Nutr. (2012) 63:767-71. doi: $10.3109 / 09637486.2012 .665043$ 
34. Guo L, Yang R, Wang Z, Guo Q, Gu Z. Glucoraphanin, sulforaphane and myrosinase activity in germinating broccoli sprouts as affected by growth temperature and plant organs. J Funct Foods. (2014) 9:70-7. doi: 10.1016/j.jff.2014.04.015

35. Gruben N, Shiri-Sverdlov R, Koonen DPY, Hofker MH. Nonalcoholic fatty liver disease: a main driver of insulin resistance or a dangerous liaison? Biochim Biophys Acta Mol Basis Dis. (2014) 1842:2329-43. doi: 10.1016/j.bbadis.2014.08.004

36. Wa R, Bradley $M$, Elliott $\mathrm{T}$. Akt/PKB activation and insulin signaling: a novel insulin signaling pathway in the treatment of type 2 diabetes metabolic dysfunction in type 2 diabetes. Diabetes Metab Syndr Obes Targets Ther. (2014) 7:55-64. doi: 10.2147/DMSO.S48260

37. Matsuda S, Kobayashi M, Kitagishi Y. Roles for PI3K/AKT/PTEN pathway in cell signaling of nonalcoholic fatty liver disease. ISRN Endocrinol. (2013) 2013:1-7. doi: 10.1155/2013/472432

38. Jin ES, Beddow SA, Malloy CR, Samuel VT. Hepatic glucose production pathways after three days of a high-fat diet. Metabolism. (2013) 62:152-62. doi: 10.1016/j.metabol.2012.07.012

39. Renee Commerford S, Ferniza JB, Bizeau ME, Thresher JS, Willis WT, Pagliassotti MJ. Diets enriched in sucrose or fat increase gluconeogenesis and G-6-Pase but not basal glucose production in rats. Am J Physiol Endocrinol Metab. (2002) 283:545-55. doi: 10.1152/ajpendo.00120.2002

40. Song S, Andrikopoulos S, Filippis C, Thorburn AW, Khan D, Proietto J. Mechanism of fat-induced hepatic gluconeogenesis: effect of metformin. Am J Physiol Endocrinol Metab. (2001) 281:275-82. doi: 10.1152/ajpendo.2001.281.2.E275

41. Herzig S, Shaw RJ. AMPK: guardian of metabolism and mitochondrial homeostasis. Nat Rev Mol Cell Biol. (2018) 19:121-35. doi: $10.1038 / \mathrm{nrm} .2017 .95$

42. WHO. UNAIDS. Neonatal and child male circumcision: a global review. Unaids. (2010) 116:1-108. doi: 10.1172/JCI29126.1784

43. Ruan H, Dong LQ. Adiponectin signaling and function in insulin target tissues. J Mol Cell Biol. (2016) 8:101-9. doi: 10.1093/jmcb/mjw014

44. Rinninella E, Raoul P, Cintoni M, Francesco F, Miggiano GAD, Gasbarrini A, et al. What is the healthy gut microbiota composition? A changing ecosystem across age, environment, diet, and diseases. Microorganisms. (2019) 7:14. doi: 10.3390/microorganisms7010014

45. Velagapudi VR, Hezaveh R, Reigstad CS, Gopalacharyulu P, Yetukuri $\mathrm{L}$, Islam S, et al. The gut microbiota modulates host energy and lipid metabolism in mice. J Lipid Res. (2010) 51:1101-12. doi: 10.1194/jlr.M0 02774

46. Gómez-Zorita S, Aguirre L, Milton-Laskibar I, Fernandez-Quintela A, Trepiana J, Kajarabille $\mathrm{N}$ et al. Relationship between changes in microbiota and liver steatosis induced by high-fat feeding-A review of rodent models. Nutrients. (2019) 11:1-30. doi: 10.3390/nu11092156

47. Li F, Hullar MAJ, Schwarz Y, Lampe JW. Human gut bacterial communities are altered by addition of cruciferous vegetables to a controlled fruitand vegetable-free diet. J Nutr. (2009) 139:1685-91. doi: 10.3945/jn.109. 108191

48. Kellingray L, Tapp HS, Saha S, Doleman JF, Narbad A, Mithen RF. Consumption of a diet rich in Brassica vegetables is associated with a reduced abundance of sulphate-reducing bacteria: a randomised crossover study. Mol Nutr Food Res. (2017) 61:1-11. doi: 10.1002/mnfr.20 1600992

49. Murphy EA, Velazquez KT, Herbert KM. Influence of high-fat-diet on gut microbiota: a driving force for chronic disease risk HHS public access. Physiol Behav. (2018) 176:139-48. doi: 10.1097/MCO.0000000000 000209

50. Liu X, Wang Y, Hoeflinger JL, Neme BP, Jeffery EH, Miller MJ. Dietary broccoli alters rat cecal microbiota to improve glucoraphanin hydrolysis to bioactive isothiocyanates. Nutrients. (2017) 9:262. doi: 10.3390/nu90 30262

51. Wu Y, Shen Y, Zhu Y, Mupunga J, Zou L, Liu C, et al. Broccoli ingestion increases the glucosinolate hydrolysis activity of microbiota in the mouse gut. Int J Food Sci Nutr. (2019) 70:585-94. doi: 10.1080/09637486.2018.1554624

52. Kaczmarek JL, Liu X, Charron CS, Novotny JA, Jeffery EH, seifried HE, et al. Broccoli consumption affects the human gastrointestinal microbiota. J Nutr Biochem. (2019) 63:27-34. doi: 10.1016/j.jnutbio.2018.09.015
53. Liu JP, Zou WL, Chen SJ, Wei HY, Yin YN, Zou YY, et al. Effects of different diets on intestinal microbiota and nonalcoholic fatty liver disease development. World J Gastroenterol. (2016) 22:7353-64. doi: 10.3748/wjg.v22.i32.7353

54. Wu C, Zhou Y, Qi G, Liu D, Cao X, Yu J, et al. Asperlin stimulates energy expenditure and modulates gut microbiota in HFD-fed mice. Mar Drugs. (2019) 17:1-13. doi: 10.3390/md17010038

55. Zhu L, Baker RD, Baker SS. Gut microbiome and nonalcoholic fatty liver diseases. Pediatr Res. (2015) 77:245-51. doi: 10.1038/pr.2014.157

56. Everard A, Lazarevic V, Derrien M, Girard M, Muccioli GG, Neyrinck AM, et al. Responses of gut microbiota and glucose and lipid metabolism to prebiotics in genetic obese and diet-induced leptin-resistant mice. Diabetes. (2011) 60:2775-86. doi: 10.2337/db11-0227

57. Hiippala K, Kainulainen V, Kalliomäki M, Arkkila P, Satokari R. Mucosal prevalence and interactions with the epithelium indicate commensalism of Sutterella spp. Front Microbiol. (2016) 7:1-13. doi: 10.3389/fmicb.2016.01706

58. Kim KA, Gu W, Lee IA, Joh EH, Kim DH. High fat diet-induced gut microbiota exacerbates inflammation and obesity in mice via the TLR4 signaling pathway. PLoS ONE. (2012) 7:e47713. doi: 10.1371/journal.pone.0047713

59. Cani PD. Gutmicrobiota and obesity: lessons from the microbiome. Brief Funct Genomics. (2013) 12:381-7. doi: 10.1093/bfgp/elt014

60. Daniel H, Gholami AM, Berry D, Desmarchelier C, Hahne H, Loh G, et al. High-fat diet alters gut microbiota physiology in mice. ISME J. (2014) 8:295308. doi: 10.1038/ismej.2013.155

61. Porras D, Nistal E, Martínez-Flórez S, Pisonero-Vaquero S, Olcoz JL, Jover $\mathrm{R}$, et al. Protective effect of quercetin on high-fat diet-induced non-alcoholic fatty liver disease in mice is mediated by modulating intestinal microbiota imbalance and related gut-liver axis activation. Free Radic Biol Med. (2017) 102:188-202. doi: 10.1016/j.freeradbiomed.2016.11.037

62. Wang CC, Yen JH, Cheng YC, Lin CY, Hisieh CT, Gau RJ, et al. Polygala tenuifolia extract inhibits lipid accumulation in 3T3-L1 adipocytes and high-fat diet-induced obese mouse model and affects hepatic transcriptome and gut microbiota profiles. Food Nutr Res. (2017) 61:1-17. doi: 10.1080/16546628.2017.1379861

63. Zou J, Chassaing B, Singh V, Pellizzon M, Ricci M, Fythe MD, et al. Fibermediated nourishment of gut microbiota protects against diet-induced obesity by restoring IL-22-mediated colonic health. Cell Host Microbe. (2018) 23:4153.e4. doi: 10.1016/j.chom.2017.11.003

64. Stefka AT, Feehley T, Tripathi P, Qiu J, McCoy K, Mazmanian SK, et al. Commensal bacteria protect against food allergen sensitization. Proc Natl Acad Sci USA. (2014) 111:13145-50. doi: 10.1073/pnas.14120 08111

65. Herp S, Brugiroux S, Garzetti D, Ring D, Jochum LM, Beutler M, et al. Mucispirillum schaedleri antagonizes salmonella virulence to protect mice against colitis. Cell Host Microbe. (2019) 25:681-94.e8. doi: 10.1016/j.chom.2019.03.004

66. El Aidy S, Derrien M, Aardema R, Hooiveld G, Richards SE, Dane A, et al. Transient inflammatory-like state and microbial dysbiosis are pivotal in establishment of mucosal homeostasis during colonisation of germ-free mice. Benef Microbes. (2014) 5:67-77. doi: 10.3920/BM2013.0018

67. Loy A, Pfann C, Steinberger M, Hanson B, Herp S, Brugiroux S, et al. schaedleri, a core member of the murine gut microbiota. mSystems. (2017) 2:e00171-16. doi: 10.1128/mSystems.00171-16

68. Zhang T, Li Q, Cheng L, Buch H, Zhang F. Akkermansia muciniphila is a promising probiotic. Microb Biotechnol. (2019) 12:1109-25. doi: 10.1111/1751-7915.13410

69. Hara A, Ota K, Takeuchi T, Kojima Y, Hirata Y, Ozaki H, et al. Dual antiplatelet therapy does not affect the incidence of low-dose aspirin-induced small intestinal injury in patients after percutaneous coronary intervation for coronary stenosis: a multicenter cross-sectional study. J Clin Biochem Nutr. (2018) 64:224-229. doi: 10.3164/jcbn.18-16

70. Tilg H, Moschen AR. Microbiota and diabetes: an evolving relationship. Gut. (2014) 63:1513-21. doi: 10.1136/gutjnl-2014-306928

71. Chelakkot C, Choi Y, Kim DK, Park HT, Ghim J, Kwon Y, et al. Akkermansia muciniphila-derived extracellular vesicles influence gut permeability through the regulation of tight junctions. Exp Mol Med. (2018) 50:e450-11. doi: $10.1038 / \mathrm{emm} .2017 .282$ 
72. Greer RL, Dong X, Moraes ACF, Zielke RA, Fernandes GR, Peremyslova E, et al. Akkermansia muciniphila mediates negative effects of IFN $\gamma$ on glucose metabolism. Nat Commun. (2016) 7:1-13. doi: 10.1038/ncomms 13329

73. Plovier H, Everard A, Druart C, Depommier C, Hul MV, Geurts L, et al. A purified membrane protein from Akkermansia muciniphila or the pasteurized bacterium improves metabolism in obese and diabetic mice. Nat Med. (2017) 23:107-13. doi: 10.1038/nm. 4236

Conflict of Interest: The authors declare that the research was conducted in the absence of any commercial or financial relationships that could be construed as a potential conflict of interest.
Publisher's Note: All claims expressed in this article are solely those of the authors and do not necessarily represent those of their affiliated organizations, or those of the publisher, the editors and the reviewers. Any product that may be evaluated in this article, or claim that may be made by its manufacturer, is not guaranteed or endorsed by the publisher.

Copyright (๑) 2021 Zandani, Anavi-Cohen, Tsybina-Shimshilashvili, Sela, Nyska and Madar. This is an open-access article distributed under the terms of the Creative Commons Attribution License (CC BY). The use, distribution or reproduction in other forums is permitted, provided the original author(s) and the copyright owner(s) are credited and that the original publication in this journal is cited, in accordance with accepted academic practice. No use, distribution or reproduction is permitted which does not comply with these terms. 